\title{
BIOPODER E RESISTÊNCIA: A (BIO)POTÊNCIA DA MULTIDÃO
}

Maiquel Ângelo D. Wermuth ${ }^{1}$ Luana Marina Santos ${ }^{2}$

BIOPOWER AND RESISTANCE: THE (BIO)POTENCY

OF THE CROWD

RESUMO: O artigo tem por objetivo central promover uma reflexão sobre o papel da biopolítica e do biopoder no mundo atual, buscando analisar como eles atuam sobre as sociedades, construindo mecanismos capazes de influenciar de forma direta a maneira como os indivíduos convivem e, da mesma forma, como eles instigam a busca de novos rumos sociais construídos através da potência de uma "multidão". O problema que orienta a pesquisa pode ser assim sintetizado: em que medida o direito de resistência encontra, na (bio)potência da multidão contemporânea, mecanismos para o enfrentamento às investidas do biopoder? O texto encontra-se articulado em três seções - as quais representam, respectivamente, os seus objetivos específicos: na primeira, busca-se abordar conceitualmente biopolítica, biopoder e resistência; na segunda, procura-se evidenciar como as categorias anunciadas na primeira seção encontram-se imbricadas nos processos econômicos da contemporaneidade; na terceira, o texto volta-se para o conceito de "multidão", a fim de apresentá-lo como condição de possibilidade para o exercício do direito de resistência. O método de pesquisa empregado é o dedutivo.

Palavras-chave: Biopolítica. Biopoder. Direito de resistência. Multidão.
ABSTRACT: The main objective of this article is to promote a reflection on the role of biopolitics and biopower in today's world, trying to analyze how they act on societies, building mechanisms that can directly influence the way individuals coexist and, in the same way, how they instigate the search for new social routes built through the power of a "multitude." The problem that guides the research can be thus summarized: to what extent does the right of resistance find in the (bio)potency of the contemporary multitude mechanisms for coping with the attacks of biopower? The text is articulated in three sections - which represent, respectively, its specific objectives: in the first, it is sought to approach conceptually biopolitics, biopower and resistance; in the second section, it is tried to show how the categories announced in the first section are interwoven in the economic processes of the contemporaneity; in the third section, the text turns to the concept of "multitude", in order to present it as a condition of possibility for the exercise of the right of resistance. The research method used is the deductive method.

Keywords: Biopolitics. Biopoder. Right of resistance. Multitude.

\footnotetext{
${ }^{1}$ Doutor em Direito Público pela Universidade do Vale do Rio dos Sinos (UNISINOS). Professor do Mestrado em Direitos Humanos da Universidade Regional do Noroeste do Estado do Rio Grande do Sul (UNIJUí) e dos Cursos de Graduação em Direito da UNIJUÍ e UNISINOS.

${ }^{2}$ Acadêmica do Curso de Graduação em Direito da Universidade do Vale do Rio dos Sinos - UNISINOS.
} 
"Eu desejo a todos, a cada um de vocês, que tenham seu motivo de indignação. Isto é precioso. Quando alguma coisa nos indigna, como fiquei indignado com o nazismo, nos transformamos em militantes; fortes e engajados, nos unimos à corrente da história, e a grande corrente da história, e essa mesma corrente, prossegue graças a cada um de nós. Essa corrente vai em direção de mais justiça, de mais liberdade, mas não de liberdade descontrolada da raposa do galinheiro. Esses direitos, cujo programa a Declaração Universal redigiu em 1948, são universais. Se você encontrar alguém que não é beneficiado por eles, compadeça-se, ajude-o a conquistá-los."

(HESSEL, 2011, p.12-13).

\section{CONSIDERAÇÕES INICIAIS}

O presente artigo - perspectivado a partir do método de pesquisa dedutivo - visa a promover uma reflexão sobre o papel da biopolítica e do biopoder no mundo atual, buscando analisar - a partir da filosofia foucaultiana e agambeniana - a forma como eles atuam sobre as sociedades, construindo mecanismos capazes de influenciar de forma direta a maneira como os indivíduos convivem e, da mesma forma, como eles instigam, de certa forma, a busca de novos rumos sociais construídos através da potência de uma "multidão" - conceito proposto na obra de Antonio Negri e Michael Hardt. Eis seu tema e objetivo geral.

Com efeito, se existe um processo de cada vez maior assunção da vida pelo poder nos moldes da proposição foucaultiana - também existe, reflexamente, uma contínua articulação de resistência a esse poder. Nesse sentido, o texto parte da seguinte problemática de pesquisa: em que medida o direito de resistência encontra, na (bio)potência da multidão contemporânea, mecanismos para o enfrentamento às investidas do biopoder?

Para responder ao problema de pesquisa, o texto encontra-se articulado em três seções - as quais representam, respectivamente, os seus objetivos específicos. Na primeira seção, busca-se abordar conceitualmente biopolítica, biopoder e resistência, a partir das obras de Michel Foucault, Giorgio Agamben e Antonio Negri e Michael Hardt; na segunda seção, o artigo busca evidenciar como as categorias anunciadas na primeira seção encontram-se imbricadas nos processos econômicos da contemporaneidade; por fim, na terceira seção, o texto volta-se para o conceito de "multidão", a fim de apresentá-lo como 
condição de possibilidade para o exercício do direito de resistência, para o que também é invocado o conceito de "indignação", oriundo da obra de Stephàne Hessel.

\title{
2 A BIOPOLÍtICA E A CAPILARIZAÇÃO DA (BIO)POTÊNCIA DA MULTIDÃO: A(S) MICRORRESISTÊNCIA(S) AO(S) PODER(ES)
}

Em seu projeto filosófico, o francês Michel Foucault (2008) procura entrelaçar com a história da modernidade mutações biológicas que acarretam transformações políticas, disseminando, portanto, a tomada de poder sobre o homem vivo. Na percepção de Foucault (2008), o limiar de modernidade biológica de uma sociedade está no momento em que o homem entra em jogo no estratagema político de um Estado. Segundo o autor (1977, p. 134),

\begin{abstract}
o homem, durante muito tempo, permaneceu o que era para Aristóteles: um animal vivo e, além disso, capaz de existência política; o homem moderno é um animal, em cuja política, sua vida de ser vivo está em questão.
\end{abstract}

Foucault (1986) se utiliza, então, do termo biopolítica para designar um estágio de poder que é posterior às práticas disciplinares antes utilizadas para governar o indivíduo e que agora passa a ser considerado como a prática de biopoderes locais. Neste contexto, a população é vista, ao mesmo tempo, como alvo e instrumento em uma relação de poder, de forma que sua vontade evidenciada possa vir a se tornar um agente de transformações da vida humana.

Antes de abarcar o conceito de "biopolítica" instituído por Foucault (1986), necessária se faz a análise das práticas disciplinares que o levaram a constituir o fenômeno biopolítico. Neste viés, Foucault (1999) coaduna a noção de disciplina com o conceito biopolítico, pois, na acepção instituída pelo autor, a noção de disciplina tangencia a necessidade de práticas disciplinares que conduzam os indivíduos, a partir do trabalho de seus corpos, a produzirem, cada vez mais, tempo e trabalho a serviço da produção capitalista. Esta submissão disciplinar acaba por assumir uma forma de governo que impera sob os indivíduos de forma individual e repetitiva, como se o poder do estado pudesse tornar o indivíduo homogêneo e massificado (WERMUTH; SANTOS, 2016).

Neste sentido é o entendimento de Salma Muchail (1985, p. 206), ao afirmar que 
as instituições disciplinares fazem funcionar um poder que, polimorfo e polivalente, não é essencialmente localizável em um pólo centralizado e personificado, mas é sobretudo difuso, minucioso, capilar" isso é, ele se descobre em múltiplos caracteres que, esquematicamente, podemos designar de econômicos, políticos, judiciários e epistemológicos. O caráter econômico do poder disciplinar é evidente, por exemplo, no caso das fabricas, pode também parecer de formas menos diretas, como no pagamento feito a hospitais.

Com efeito, Foucault (1986), ao analisar o conceito disciplinar, prepara o caminho para a concepção de biopolítica. Para o autor, enquanto a técnica disciplinar é vista como uma técnica "centrada no corpo, que produz efeitos individualizantes por meio da manipulação do corpo como foco de forças que é preciso tornar úteis e dóceis ao mesmo tempo", a biopolítica, por sua vez, é vista como uma tecnologia que não mais está centrada no corpo individual, mas sim, "na vida enquanto fenômeno" (WERMUTH; SANTOS, 2016, p. 413).

Ao considerar a biopolítica como uma tecnologia que procura recolocar os corpos nos processos biológicos de conjunto, Foucault (1999), esclarece que ela atua como um instrumento de gerenciamento, que não mais se estabelece sob um pilar que procura "matar a vida", mas sim, como um poder que a gerencia (WERMUTH; SANTOS, 2016).

Como destaca Ayub (2015, p. 68), "a tecnologia de poder que consiste numa espécie de estatização do biológico, ao contrário do poder disciplinar, não opera no nível dos corpos individualizados, mas sobre o conjunto da população". Logo, "se o poder disciplinar se orienta do sentido da individualização, o poder regulamentador segue o princípio da massificação. Os alvos do exercício do poder do Estado passam a ser os efeitos e processos gerados pela vida em conjunto."

Esta passagem do poder disciplinar para a instauração de uma política voltada sobre a vida, de acordo com Foucault (1986), se deu, principalmente, em razão do capitalismo desenvolvido no século XVIII, "responsável pela socialização de um primeiro objeto que foi o corpo enquanto força de produção, de trabalho". Neste aspecto, o capitalismo teria instituído a entrada da vida humana no sistema capitalista, razão pela qual, considerar-seia fundamental instrumentalizar o saber sobre a vida, a fim de "controlar as consequências 
dos fenômenos naturais de modo que elas signifiquem ganhos econômicos" (WERMUTH; SANTOS, 2016, p. 415).

De acordo com Judith Revel (2005), o termo biopolítica designa a maneira pela qual o poder tende a governar o mecanismo de vida dos indivíduos. De acordo com a autora (2005, p. 26), a biopolítica

\begin{abstract}
designa a maneira pela qual o poder tende a se transformar, entre o fim do século XVIII e o começo do século XIX, a fim de governar não somente os indivíduos por meio de um certo número de procedimentos disciplinares, mas o conjunto dos viventes constituídos em população: a biopolítica, por meio dos biopoderes locais, se ocupará, portanto, da gestão da saúde, da higiene, da alimentação, da sexualidade, da natalidade, etc, na medida em que elas se tornaram preocupações políticas.
\end{abstract}

No mesmo sentido, Ayub (2015, p. 63), explica que "saberes como demografia, estatísticas, sociologia e gestão publica integram o conjunto de saberes e tecnologias de poder que caracterizam o pode disciplinar", de modo que a transição destes para o instituto da biolítica se vem a se complementar, finalmente, a partir do momento em que “estas mesmas técnicas disciplinares que, em um primeiro momento, atuam sobre o corpo do indivíduo, se juntam ao poder regulamentador que incide sobre os processos globais gerados no seio da população".

Foucault (1994, p. 210), nesse sentido, assevera que "o controle da sociedade sobre os indivíduos não se efetua somente pela consciência ou pela ideologia, mas também no corpo e com o corpo". Mais além, no mesmo aspecto, Laura Bazzicaluppo (2017, p. 15-16) procura solidificar o conceito de biopolítica, ao lecionar que a biopolítica transmuta sob os aspectos do homem como "ser vivente". A biopolítica, por si só, seria capaz de envolver fenômenos biopolíticos diretamente ligados com a vida biológica dos indivíduos, "como se a política tivesse assumido para si a gestão da vida biológica".

Dessa forma, a biopolítica intervém nos processos biológicos dos indivíduos, tais como o nascimento, a morte, a doença, a produção, etc, ou seja, os chamados "fenômenos de massa". O Estado realiza cálculos de gestão de poder para controle de populações conforme certos mecanismos, tais como previsões e estatísticas globais para intervir nos fenômenos gerais (BITTENCOURT, 2015). 
Nesta senda, percebe-se que os pequenos fragmentos da vida política se baseiam, principalmente, na necessidade de se adaptar à existência dos indivíduos na própria polis, na qual os poderes destes mesmos indivíduos pendem a constituir as formas de relação entre o soberano e o cidadão. De acordo com os ensinamentos de Foucault (2008), a biopolítica nada mais é senão o governo da vida, a partir da qual se permite traçar o sentido da vida em sociedade em prol desta própria vida.

Considerando, portanto, que a biopolítica está centrada nos mecanismos do ser e nos processos biológicos dos indivíduos, cumpre esclarecer que o termo tem, por objeto, o próprio ser que é afetado por tais mecanismos. O termo, que designa a entrada do corpo e da vida na política, é capaz de colocar como ser passivo o corpo da população, ou seja, sua própria vida como um agente de transformação da vida humana (PELBART, 2003).

De acordo com Foucault (2008), o fenômeno biopolítico passa a transcender a barreira instituída pela soberania. Não se trata mais daquele poder soberano que detém o domínio sobre a morte e a vida do indivíduo, mas, sim, sobre uma intersecção do poder que gera a vida, o poder viver.

A biopolítica, neste aspecto, gerencia formas de vida, vista como uma assunção da vida pelo poder. Aquilo que Foucault (2008) denomina como "poder", consolida-se através de simples atos reiterados das próprias relações familiares, seja na supremacia dos pais para com os filhos ou, muitas vezes, do próprio homem com a mulher, em sociedades patriarcais. Para Foucault (2008), as relações hierárquicas de poder do Estado se utilizam, principalmente, das próprias táticas de poder do próprio ser.

Assim, o poder soberano - instituído pela máxima "fazer morrer e deixar viver" converteu-se para um novo direito que tem por lema "fazer viver e de deixar morrer". Com efeito, a vida, que agora representa a multiplicidade de humanos, passou a se sobrepor à técnica de controle dos indivíduos pelas formas de disciplina, vigilância e normalização focadas essencialmente nos seus corpos individuais, dando ênfase ao agrupamento de seres que forma uma massa global afetada por processos de conjunto (BITTENCOURT, 2010).

Ainda sobre o poder, Foucault (2008) acredita que este pode ser visto como algo que circula e funciona em cadeia: o indivíduo, neste segmento, nada mais é senão um 
efeito do próprio poder. De acordo com o autor (2008), o conceito da efetividade do poder está investido em práticas reais. Neste sentido, não há que se falar em um fenômeno de controle cerrado e homogêneo de um indivíduo sobre outro; não se trata, somente, de quem tem o poder e daqueles que lhe são subordinados.

Foucault (2008) vai mais além quando questiona sobre a real intenção do governo em relação às suas normas mandamentais para com a população que lhe é subordinada. 0 filósofo explica que, para que o governo possa, efetivamente, melhorar a saúde e as condições da vida de uma população, deve preocupar-se, substancialmente, com os fragmentos da vida humana, na sua mais pura essência. Assim, o poder do soberano não se limita unicamente ao ato governamental, mas, além desta condição, integra-se a uma faceta de controle e dominação.

Em um contexto tal, segundo Foucault (2008, p. 302),

as guerras já não se travam em nome do soberano a ser defendido; travam-se em nome da existência de todos; populações inteiras são elevadas à destruição mútua em nome da necessidade de viver. Os massacres se tornaram vitais. Foi como gestores da vida e da sobrevivência dos corpos e da raça que tantos regimes puderam travar tantas guerras, causando a morte de tantos homens. E, por uma reviravolta que permite fechar o círculo, quanto mais a tecnologia das guerras voltou-se para a destruição exaustiva, tanto mais as decisões que as iniciam e encerram se ordenaram em função da questão nua e crua da sobrevivência.

Pode-se, com isso, dizer que a biopolítica e o biopoder imperam sobre as mais diversas formas de controle, mormente por se entrelaçarem com a necessidade da manutenção da ordem e ao controle dos afazeres dos indivíduos. Assim, muitas vezes, estes controles de poder acabam por atuar de forma contrária à própria vida e, neste caso, o reflexo deste poder acaba, muitas vezes, na medida em que invade e destrói e promove desocupações, gerando um efeito negativo, não mais sobre a prevalência da vida, mas, sim, como uma atuação que procura ensejar a morte e a dor em uma sociedade. (FOUCAULT, 2008).

Para Bazzicaluppo (2017), na medida em que as sociedades se assemelham, tornarse-ia menos trabalhoso ao poder estatal domar os indivíduos governados. Nessa perspectiva, o foco na biopolítica não versa mais sobre a singularidade do indivíduo, mas em formas de poder que objetivam estados de regularidade: "com efeito, na medida em 
que se normaliza a população em que se regulamenta a população, torna-se mais fácil controlá-la e otimizar a sua produtividade" (WERMUTH; SANTOS, 2016, p. 417).

Impera, portanto, diante deste controle desmedido, que, por consequência, aliena o indivíduo da cena política, uma biopolítica de caráter negativo. Para Rawls (1981) o exercício do poder do soberano, quando não reflete uma sociedade pautada no exercício de uma cidadania participativa desconhecendo, por consequência, direitos humanos e fundamentais, acaba por refletir os efeitos de uma biopolítica negativa, em razão da gravidade que os indivíduos suportam perante a ausência destas garantias.

Nesse aspecto, Marques (2016) acredita que a biopolítica inverte sua definição primária: não se trata mais de deixar viver, o que evidencia que a biopolítica passa, portanto, a demonstrar uma faceta contrária, qual seja, a de fazer morrer. Nese viés, torna-se imperativa a necessidade dos indivíduos de se insurgirem contra a violação deliberada de um Estado que, ao invés de assegurar direitos básicos aos indivíduos, acaba violando e não assegurando princípios fundamentais.

No mesmo sentido, Pelbart (2003), ao afirmar que biopolítica, por rechear-se daquilo que alimenta a vida, mudou a perspectiva da política, trazendo mudanças estruturais que contribuem no aumento da expectativa de vida, voltando-se ao bem estar dos cidadãos, traz, também, o reflexo negativo destas ações, estabelecendo uma linha tênue entre a política que faz aumentar a vida e que, na sequência, a destrói por um mero descuido político, inviabilizando e engessando a vida pública com as suas consequências.

Foucault (1999) faz uma análise diametralmente oposta à fundamentação do poder soberano como único operante de fonte detentora de poder. Para ele, necessária se faz a insurgência de um poder pautado nas relações de força de todas as relações sociais. Neste sentido, o autor acredita que a estruturação de uma sociedade deve ser pautada nos opostos relacionais dos indivíduos, bem como a ação e a reação dos governados, razão pela qual Foucault (1999) insiste em dizer que, quando apenas um exerce o poder sobre outros, este deve compreender que a revolta destes poderá ser exercida apenas contra um.

Baseado nos institutos disciplinares abarcados por Foucault (1986), bem como a partir da ideia de como estes mesmos institutos deram origem a mecanismos biopolíticos, pautados não mais controlar somente um corpo individual, mas que exercem um controle 
sobre as massas, a fim de "controlar as consequências dos fenômenos naturais de modo que elas signifiquem ganhos econômicos" (WERMUTH; SANTOS, p. 422), é que os próximos tópicos se inserem.

Far-se-á uma análise destes institutos, baseando-se, substancialmente, na influência capitalista surgida no alvorecer do século XIX, que se utilizou da biopolítica para ligar os homens ao aparelho de produção, utilizando-se de uma série de operações voltadas a extrair dominar os corpos destes indivíduos, para, finalmente, adestrá-lo, “a fim de que este se torne força de trabalho, colocando seu corpo a favor do capital" (ESCOBAR, 1985, p. 214). Mais do que isso, será abarcado, ainda, como o instituto do biopoder, que procura tornar a vida humana produtiva a partir de mecanismos que fragmentam o censuram o processo biológico dos seres, a fim de, em um primeiro momento, exclui-los e individualizá-los, também integra e fomenta as mais variadas formas de resistências individuais e coletivas.

\section{REINVENTANDO COORDENADAS DE ENUNCIAÇÃO: A BIOPOLÍTICA, O BIOPODER E OS REFLEXOS DO CAPITAL NO MUNDO CONTEMPORÂNEO}

De acordo com o que foi até aqui apontado, por muito tempo, o Estado preocupouse, significativamente, em promover o controle dos indivíduos em prol de uma produção que fomentasse o desenvolvimento capitalista. Mais tarde, essa perspectiva disciplinar passa a se entrecruzar com a perspectiva biopolítica, oportunidade na qual o poder passa a se ocupar, também, com fenômenos de massa próprios de uma população (natalidade, morbidade, etc). Isso revela que os sujeitos - seja na perspectiva individual (disciplinar), seja na perspectiva de população (biopolítica) - "se tornam, no desenvolvimento do Estado moderno, coisas importantes para o poder" (NEGRI; HARDT, 2012).

A inserção da lógica do capitalismo na gestão da vida humana pormenorizou os institutos da biopolítica. É a partir dele que se instrumentaliza a necessidade do saber sobre a vida. É dele que decorre a viabilização do controle das pessoas - e, mais tarde, populações - nos próprios processos de produção, o que intui, neste sentido, que o objetivo do Estado se paute, substancialmente, no controle de fenômenos naturais -morte 
e nascimento - aos processos econômicos, pois, na medida em que se controla os indivíduos, torna-se mais fácil otimizar a sua produtividade (PELBART, 2003).

Vista como uma forma de controle das condutas inerentes às coletividades humanas, a biopolítica conduz ao compromisso dos próprios indivíduos atuarem em prol daquilo que vivem e produzem. Os dados ontológicos que envolvem a vida humana conduzem o indivíduo moderno a reconhecer, em si próprio, sua capacidade de interação e transformação do meio em que está inserido (BAZZICALUPPO, 2017).

Em seu curso "Em defesa da Sociedade", Foucault (1999) direciona-se ao entendimento de que o indivíduo, além de ser efeito de um poder, pode ser visto, também, como uma espécie de intermediário de poder. Neste curso, Foucault (1999) faz inúmeras referências à governamentabilidade liberal, trazendo ao âmago da questão a necessidade de que um verdadeiro Estado democrático deve ser alimentado por políticas voltadas ao "fazer viver".

Nesse sentido, Foucault (2008) explica que, muitas vezes, o indivíduo não percebe o poder que detém em razão do gigantesco mercado de consumo que procura, acima de tudo, promover alienações aos indivíduos. Neste aspecto,

uma reorganização interna que, mais uma vez, não pergunta ao Estado que liberdade você vai dar à economia, mas que pergunta à economia: como a sua liberdade vai ter uma função e um papel de estatização, no sentido de que isso permitirá fundar efetivamente a legitimidade de um estado? (FOUCAULT, 2008, 304).

Para além de Foucault (2008), o termo "biopolítica" deixa de ser prioritariamente a perspectiva do poder e de sua racionalidade, tendo por objeto passivo o corpo da população e suas condições de reprodução. É possível encontrar, uma outra definição de "biopolítica" nos ensinamentos de Pelbart (2003, p. 25), que assim leciona:

a própria noção de vida deixa de ser definida apenas a partir dos processos biológicos que afetam a população. Vida inclui a sinergia coletiva, a cooperação social e subjetiva no contexto de produção material e imaterial contemporânea, o intelecto geral.

Ante a análise daquilo que pressupõe essa definição de "biopolítica", percebe-se que o termo ganhou uma amplitude inesperada, evidenciando que a vontade humana também tem o condão de afetar e ser afetada em toda sua amplitude, no intuito de 
reinventar suas coordenadas de enunciação. "De maneira mais ampla e positiva, essa potência da vida no contexto contemporâneo, equivale, precisamente, à biopotência da multidão" (PELBART, 2003, p. 25).

De acordo com o mesmo autor, a capacidade de produzir o novo não é prerrogativa dos grandes gênios. Qualquer ser é capaz inventar. A invenção, portanto, é prerrogativa do homem comum, seja ela produzida nas conversas ou no próprio lazer cotidiano. Ocorre que essa mesma capacidade social, em que pese esteja espalhada por todos os cantos, encontra-se subordinada aos ditames impostos pelo capital (PELBART, 2003).

Trata-se de uma economia viva, latente em quantidade social e potência psíquica. De acordo com Pelbart (2003), essa mesma potência é incisivamente controlada pelo poder do Império ${ }^{3}$, que procura regular e controlar a força vital dos indivíduos.

A potência de vida da multidão, no seu misto de inteligência coletiva, afetação recíproca, produção de laço, capacidade de invenção de novos desejos e novas crenças, de novas associações e novas formas de cooperação, é cada vez mais a fonte primordial de riqueza do próprio capitalismo. Uma economia imaterial que produz sobretudo informação, imagens, serviços, não pode basear-se na força física, no trabalho mecânico, no automatismo burro, na solidão compartimentada. São requisitados dos trabalhadores sua inteligência, sua imaginação, sua criatividade, isto é, sua própria vida como fonte de valor (PELBART, 2003, p. 25).

Não há como conceituar o termo biopolítica sem caracterizar o instituto do biopoder, que, por sua vez, institui o momento em que a vida passa a fazer parte do campo do poder, onde o principal objetivo de um Estado, norteia a necessidade de controlar os indivíduos como massa uniforme. Com o biopoder, seria possível, portanto, instaurar mecanismos que tornem a população cada vez mais produtiva (WERMUTH; SANTOS, 2016).

Se, na definição de Foucault (2008), o biopoder procura exercer mecanismos de controle a serviço da cumulação capitalista, para Hardt e Negri (2012), o biopoder é visto, também, como a sequela de uma reinvenção de poderes, expandindo todas as formas da

\footnotetext{
3 O termo "Império", proposto pelos autores Hardt e Negri, procura conceituar as relações de poder na atualidade. Para os autores, o termo abarca um poder transcendente e opressor, que busca manejar, seduzir e explorar a mente de seus governados, evidenciando uma relação de poder e dominação que excede os limites de uma governabilidade democrática.
} 
vida humana. Para Hardt e Negri (2012), quando da análise do biopoder, Foucault, não teria analisado este instituto como uma fonte de poder provinda da própria relação de processo produtivo do indivíduo. Isso porque, para aqueles, o biopoder abarca a totalidade de um corpo social, não tão somente o poder de produção do capital.

Por exemplo, não caberia, na sua análise da produção social, a capacidade criativa e produtiva forjada pela necessidade de sobrevivência de indivíduos à margem do mundo do trabalho, ou de situações que estejam diretamente relacionadas com o processo alternativo de produção. Para isso, Negri introduziu na sua análise a nova natureza do trabalho produtivo, não mais se valendo da distinção das várias dimensões da vida social, como a econômica, política, social e cultural (MONTEIRO, 2003, p. 166).

Nesse mesmo sentido é o entendimento de Pelbart (2003, p. 23), quando afirma que todos produzem constantemente, mesmo não estando vinculados ao próprio processo produtivo, o que demonstra que "produzir o novo é inventar novos desejos e novas crenças, novas associações e novas formas de cooperação." Nesse sentido, o poder desenvolvido pelos indivíduos não se sujeita unicamente ao processo de um capital insaciável; esse poder, proveniente dos mais diversos instrumentos de valorização social, se torna "fonte primordial de riqueza do próprio capitalismo" (PELBART, 2003, p. 23).

No contexto de um capitalismo cultural, que expropria e revende modos de vida, não haveria uma tendência crescente, por parte dos chamados excluídos, em usar a própria vida, na sua precariedade de subsistência, como um vetor de autovalorização? Quando um grupo de presidiários compõe e grava sua música, o que eles mostram e vendem não é só sua música, nem só suas histórias de vida escabrosas, mas seu estilo, sua singularidade, sua percepção, sua revolta, sua causticidade, sua maneira de vestir, de "morar" na prisão, de gesticular, de protestar, de rebelar-se - em suma, sua vida. Seu único capital sendo sua vida, no seu estado extremo de sobrevivência e resistência, é disso que fizeram um vetor de existencialização, é essa vida que eles capitalizaram e que assim autovalorizou e produziu seu valor." (PELBART, 2003, p. 25).

Para Negri e Hardt (2012, p. 41), a biopolítica se concentra em localizar "os meios e as forças de produção da realidade social e as subjetividades que a animam", enquanto que o biopoder, por sua vez, age como integrador das capacidades dos seres, a partir das quais uma sociedade é capaz de apropriar-se da própria reprodução da vida, totalizando toda a capacidade de consciência das relações sociais. Para Monteiro (2012, p. 167), "estrategicamente, os mecanismos de controle são introjetados pelos indivíduos, por meio 
dos seus corpos e cérebros, e passam a valer como referências que indicam a integração ou exclusão social".

Nesta perspectiva, na qual o biopoder atua significantemente no processo voltado para o acúmulo econômico, percebe-se que sua definição acaba se perpetuando, em verdade, no momento em que a efetividade do poder escapa do comando do soberano, aterrissando, dessa forma, na força vital do indivíduo, capaz de abarcar um "jogo antagônico de múltiplas singularidades", no qual "o corpo social e a produtividade são totalmente incorporados pelos dispositivos do poder" (MONTEIRO, 2003, p. 167).

Ocorre que, como já exposto, toda e qualquer prática de controle e dominação reflete sobre os indivíduos como práticas de resistência. Se há, de um lado, o exercício de práticas de dominação que exercem controle sobre os indivíduos perante o Estado, existe por outro, "o resultado disso: a reação em cadeia através de inúmeros elementos coordenados e encadeados num sistema de múltiplas subjetividades relacionais" (MONTEIRO, 2003, p. 167).

Assim, em razão da multiplicidade dessa subjetivação relacional, não há que se falar em resistência una do indivíduo, mormente porque este, sozinho, não é capaz de resistir àqueles que Ihe exercem o controle. Identifica-se, aí, uma resistência do povo como multidão, quando esta se utiliza da transição linear de sociedade de controle, utilizando-se de todos os meios do saber e não se limitando, finalmente, à disciplina do espaço fabril, mas, mais além, aperfeiçoando formas de controle intrínsecas ao homem enquanto espécie.

Nesse sentido Pelbart (2003) acredita que as bases de uma vida, quando dominada por mecanismos de controle, são capazes de agir não tão somente em prol de um "império", mas, também, de afetar a vida em sociedade. Isso, de forma ampla, "significa reconhecer que nele o poder sobre a vida atinge uma dimensão nunca vista, mas por isso mesmo nele a potência da vida se revela de maneira inédita" (PELBART, 2003, p. 83). Para Pelbart (2003), a dominação de uma multidão pode significar, também, uma forma de resistência ativa.

A biopolítica, em sua essência, aplica-se à população na medida em que possui interesse em lhes governar a própria vida, de modo que esta acaba por fazer parte do 
próprio campo do poder. Quando o cidadão procura posicionar-se diante da esfera em que se encontra, necessita fazer uso de sua própria condição humana, a fim de se envolver com o social e com o projeto de seus governantes (BAZZICALUPPO, 2017).

Neste sentido, traz-se, como fins exemplificativos, os apontamentos do livro "O espírito das leis", de Montesquieu (2005), que tangencia e coaduna o exercício da cidadania vinculado com a participação da população dentro da vida política. Montesquieu (2005) acredita que a vida política penetra na vida de todos os indivíduos suscitando a participação destes para que se possa alcançar um novo cenário. Para o filósofo, quando um governo é capaz de sedimentar seus próprios princípios, este acaba por si próprio, corrompendo-o.

Quando tais princípios se perdem ou, inclusive, quando levados ao extremo, a democracia tende a desmoronar. De acordo com Montesquieu (2005), existe uma linha tênue que induz o soberano a aceitar sua condição de obediente e de querer romper com a ordem para também exercer o poder de mando. Neste sentido:

\begin{abstract}
a democracia deve evitar dois excessos: o espirito da desigualdade, que leva à aristocracia, ou o governo de um só, o espírito de igualdade extrema, que a leva ao despotismo de um só, assim como o despotismo de um só termina com a conquista. (MONTESQUIEU, 2005, p. 122).
\end{abstract}

Para Müller (2004, p. 53), o poder constituinte apenas pode ser visto em seu aparato democrático na medida em que legitima a prática instituinte como norma. Isso quer dizer que a prática do exercício do direito, quando fundada constitucionalmente, deve, impreterivelmente, estar ligada à legitimidade do ato fundador, a fim de buscar a "legitimação por meio da permanência da práxis constitucional no cerne material". Ocorre que, para Müller (2004), o exercício do poder estatal no atual sistema carece de justificação democrática. Nesse sentido, não há que se falar em proteção ao poder arbitrário, mormente porque a representação de poderes não dá ensejo à delegação de poderes absolutos.

A prática duradoura de fazer valer as leis constitucionais não está associada à ideia de poder permanente. Para Mouffe (2003), a potência do poder cumpre ao povo, de forma plural, o exercício da escolha. 
O que é uma "sociedade democrática"? É uma sociedade pacificada e harmoniosa onde as divergências básicas foram superadas e onde se estabeleceu um consenso imposto a partir de uma interpretação única dos valores comuns? Ou é uma sociedade com uma esfera pública vibrante onde muitas visões conflitantes podem se expressar e onde há uma possibilidade de escolha entre projetos alternativos legítimos? [...] o tipo de política democrática dominante atualmente não pode nos ajudar a entender a importância do dissenso numa sociedade democrática. Ela é incapaz de captar as diferentes formas de antagonismos que emergem em nosso mundo globalizado, pós-guerra fria, e de enfrentar um tipo de política democrática que poderia dar conta deles. (MOUFFE, 2003, p. 1).

Tais ensinamentos deixam clara a consciência e a importância de uma biopotência coletiva. Cada ser, dotado de peculiaridades, é capaz de produzir e dar origem às mais diversas formas de criação e sinergias coletivas. Não se trata mais do trabalhador que é posto a trabalhar com o corpo que apenas lhe serve de suporte, mas sim, da criação vital e cognitiva fundada com a alma do próprio indivíduo. "É como se as máquinas, os meios de produção tivessem migrado para dentro da cabeça dos trabalhadores e virtualmente passassem a pertencer-lhe. Sua imaginação ciência, própria fonte de valor" (PELBART, 2003, p. 24).

A biopotência, quando vista através do poder de agir do indivíduo, representa, por sua vez, um avanço das questões que, antes, se voltavam para o minimalismo da vida, para, então, voltar-se para preocupações mundiais. O indivíduo moderno, assim visto, é capaz de traçar paralelos entre o compromisso de uma vida humana preocupada em atuar em favor do meio em que vive.

Para Foucault (2004, p. 78), o exercício da resistência possui caráter imperativo. Isso porque "a subjetividade (não a dos grandes homens, mas a de qualquer um) se introduz na história e Ihe dá o seu alento". Foucault (2004), nessa linha, já acreditava que, onde há o exercício do poder, há, também, o predomínio de uma resistência. O que importa, para Foucault (2004), não se pauta na veracidade das vozes daqueles que resistem, mas, simplesmente, na sua existência. Para o filósofo (2004, p. 80), "basta que elas existam e que tenha, contra elas tudo o que se obstina a fazê-las calar, para que faça sentido escutálas e buscar o que elas querem dizer".

A partir desta releitura do que consiste o conceito de biopoder, é possível verificar que este novo conceito procura fazer uma ponte acerca do exercício da resistência na 
contemporaneidade. Assim, é possível entender o biopoder como um instituto que "evoca uma nova modalidade de resistência, não como antes, proveniente de um partido, de uma minoria, mas de uma singularidade qualquer, do qualquer um" (FELICIO, 2008, p. 11). Pelbart (2003, p. 141), neste sentido, salienta que "singularidades que declinam toda identidade e toda condição de pertinência, mas manifestam seu ser comum - é a condição, dizia Agamben há vários anos, de toda política futura”.

Nesse sentido, Agamben (2013), ao analisar a noção de comunidade, sugere que o homem que nela habita não deva se sujeitar a qualquer tipo de divisões e partilhas (cor, raça, etnia). Para o autor "o ser que vem é o ser qualquer", o indivíduo, neste aspecto, não pode estar atrelado àquelas características comuns que o obrigam a aderir um grupo ou uma classe, ele é, por si só, aquilo que simplesmente "é".

Essa afirmação abre pressupostos para articular o pensamento da comunidade sobre o termo que o autor insiste em prevalecer, o "qualquer". Agamben explica que a noção de comunidade não deve apropriar-se de características específicas e partilhadas para fins enquadrar o indivíduo em determinados grupos. Em verdade, o autor fundamenta a necessidade de inclusão e possibilidade de simplesmente "ser", sem qualquer tipo de características pré-definidas (AGAMBEN, 2013).

Com efeito, o que é relevante para a abordagem de Agamben (2013), não é a singularidade como tal, mas, sim, a sua inclusão em uma identidade qualquer. Para o autor, o Estado não suportaria que o próprio ser "qualquer" seja retomado sem uma identidade específica,

Um ser que fosse radicalmente privado de toda identidade representável seria para o Estado absolutamente irrelevante. É isso que, na nossa cultura, o dogma hipócrita da sacralidade da vida nua e as declarações vazias sobre os direitos do homem têm a tarefa de esconder. Sacro aqui não pode ter outro sentido senão aquele que o termo tem no direito romano: sacer é aquele que foi excluído do mundo dos homens e que, embora não podendo ser sacrificado, é lícito matar sem cometer homicídio. (AGAMBEN, 2013, p. 79).

Nesse sentido, fala-se de um ser que, ao habitar a "comunidade que vem", permanece inacabado e, mais ainda, permanece singular e aberto a conceber outras possibilidades em uma sociedade que está por vir, sem soberania definida, aberta e 
disposta a se consolidar "de qualquer forma", sem qualquer tipo de estruturas sociais prédispostas (AGAMBEN, 2013).

Para isso, é preciso pensar além do sujeito, uma comunidade sem soberania onde as formas de vida se consolidem em forma múltipla, contínua e inacabada. Ocorre que, para Agamben (2013), a crise política representacional é incapaz conter o fluxo intenso de variações. Conceber o indivíduo em sentido homogêneo seria trazer à tona todas as formas totalitárias de poder que optam por excluir aqueles que não pertencem a determinado grupo e que, evidentemente, falharam em sua proposta.

Nesta linha, torna-se imprescindível entender indivíduo como um ser singular, sem procurar enquadrá-lo em conceitos que proponham excluí-lo de uma massa dominante, para, finalmente, abarcar a vida com sentido afirmativo.

Nesse rumo, a próxima seção procura compreender de que forma o indivíduo pode, por si só, através de suas singularidades múltiplas, romper com determinismos préconcebidos, para, enfim, buscar novas formas de vida aquém daquelas codificadas pela sociedade. Neste viés, fala-se não mais sobre mecanismos de controle que antes serviam para designar formas de vida, mas como estes atuam como forma de potencialização desta forma de vida, de modo a incluir, nesta acepção predominantemente biológica, "a sinergia coletiva, a cooperação social e subjetiva no contexto de produção material e imaterial contemporânea, o afeto, o desejo, enfim, o 'poder de afetar e ser afetado'" (PELBART, 2003, p. 25).

\section{A (BIO)POTÊNCIA DA MULTIDÃO COMO ESTRATÉGIA DE RESISTÊNCIA}

Conforme a abordagem até aqui realizada, tem-se que o biopoder norteia a necessidade de controlar os indivíduos como massa uniforme, com o principal objetivo de extrair a produtividade máxima dos indivíduos. Como visto, muitas vezes, tal controle acaba revelar uma faceta perversa do ente estatal, trazendo a necessidade de recusa dos indivíduos a cumprirem com determinadas obrigações, como forma de contenção de uma faceta extrema de controle, que, muitas vezes, acabam não resistindo às formas de dominação em razão de uma busca incansável voltada para o acúmulo do capital.

Arendt (2009), nesse sentido, enfatiza que, em razão de um sistema voltado para o 
capital, o homem optou por isolar-se da esfera pública em detrimento de si mesmo. Em razão de uma necessidade exacerbada voltada ao acúmulo de bens, o homem, conceituado pela autora como homo faber, concentrou suas vontades em si próprio, esquecendo-se, portanto, pela forma como as leis se aplicam aos indivíduos. Para Arendt, no entanto, a condição da vida humana deve ser vista como preocupação primordial, tanto dos governos, quanto dos próprios governados, estando ela presente nas pautas de discussões de uma vida pública, trazendo a relevância, inclusive, de uma política voltada à solidariedade e à aplicação dos direitos humanos.

Logo, em razão daquilo que aponta Arendt (2009), o campo social, carregado de ação da vida ativa e que deveria, por si só, ter o objetivo de integrar a todos, acaba, por outro lado, não cumprindo o seu real intento, padecendo sobre o real exercício da capacidade humana em participar da esfera pública. Para Arendt (2009), os indivíduos, se pudessem fazer valer seu real papel dentro da vida política, ao ocupar os espaços públicos de uma sociedade, poderiam exercer uma liberdade harmônica ao interagir com outros indivíduos que compartilhassem dos seus objetivos.

Civilidade é quando interagirmos com pessoas estranhas, sem q essa estranheza ou frieza possa contaminar laços de interação. Capacidade de conviver com as diferenças, aceitar outras propostas, para, finalmente, adquirirmos e ampliarmos nossos entendimentos em relação à vida e à civilidade (MARQUES, 2016, p. 127).

A sinergia coletiva, inerente à participação coletiva dos indivíduos, possui espaços vastos para exercer seu dinamismo. Entender a pluralidade dos indivíduos, através de inserções e grupos participativos, é requisito imperioso para que, aqueles que não se ajustem às leis, não se sintam isolados do mundo da vida. Afinal, como salienta Bauman (2001, p. 187) "vazios são os lugares em que não se entra, não se acolhe, e onde se sentiria perdido e vulnerável, surpreendido e um tanto atemorizado pela presença de humanos". Nesse sentido, é possível entender que o processo comunicativo permeia a sociedade substancialmente, com o objetivo de integração.

De acordo com Foucault (2008), os indivíduos acabariam encontrando problemas para a aplicabilidade de certos anseios em razão dos mecanismos de controle exercidos pelos detentores de poder, os quais persistem em inviabilizar o exercício de uma democracia voltada para a liberdade do cidadão social. Mas, também, de acordo com 
Foucault (2008), em que pese a ideia do poder localizado com um único detentor, acabou por tirar o indivíduo da vida pública, este mesmo sujeito, vigiado por uma constância de regras voltadas para regular sua vida no âmbito social, pode, de acordo com o que aqui demonstrado, reconhecer que é capaz, por si só, de exercer transformações no meio em que está inserido, fazendo uso das próprias práticas utilizadas pelos detentores de poder, dando ensejo ao biopoder "positivo".

“Dizer que o poder teria dominado a vida ou dela tomado posse, é dizer que ele se incumbiu dela, é dizer que conseguiu cobrir a superfície que lhe corresponde" (MARQUES, 2016, p. 124). Assim, constata-se que, quando o poder age através de mudanças sistêmicas, voltadas para o aumento da vida e o controle de acidentes, acaba por estimular, por reflexo, a ação do indivíduo na esfera governamental. A visão de que a ciência está apta a reestruturar a formação da vida pública, acaba, muitas vezes, obstruindo a vida pública com seus reflexos negativos que, muitas vezes, ao querer aumentar a vida, o homem, fazendo uso de armamentos e instrumentos de toda espécie, acaba, na sequência, destruindo-a.

Para que o real exercício de uma política baseada em princípios democráticos se torne verdadeiramente eficaz, talvez, necessária a presença do cidadão como participante atuante da vida política. Não há que se falar em direitos e garantias apenas para alguns, mas sim, para todos. Uma sociedade pautada em pilares basilares de Direitos Humanos, apenas se concretiza com uma comunicação verdadeiramente construída na esfera pública, razão pela qual, revitalizar o processo de atuação é tarefa de todos, a fim de priorizar um diálogo voltado à própria vida, pois esta, "é ponto essencial na modernidade com tantos recursos disponíveis para cumprir a tarefa da biopolítica nas esferas em que pertencemos" (MARQUES, 2016, p. 130).

Assim, nessa ponte entre o poder da criação do indivíduo e da biopotência do coletivo, aterrissa-se nas possibilidades de uma democracia biopolítica. A riqueza de uma multidão, dotada de numerosos corpos vitais, tem o condão de reconfigurar cenários políticos que se encontram voltados para a disseminação de uma produção capitalista. Para Foucault (2008), a resistência ao poder apoiado na vida bióloga dos indivíduos, se daria em razão de sua investidura, qual seja, a própria vida. 
Virno (2013), explica que a potência da vida no contexto contemporâneo é vista de maneira mais ampla e positiva, e não somente como um instrumento controlador da existência humana. É, a partir daí, que se insere a necessidade pungente de fazer valer aquilo que uma multidão é capaz de perfectibilizar. E o qual o conceito de multidão? Esta, conforme Virno (2013), indica, muitas vezes, um aglomerado indomável que cabe ao governante dominar, enquanto que o povo, por sua vez, representaria um corpo público animado por uma vontade única.

De fato, o conceito de multidão não reflete o conceito de um povo, uma vez que este não procura representar, unicamente, a vontade de uma grande maioria de forma uníssona. A multidão pode ser vista, nesse aspecto, como o oposto da massa.

Massa são abolidas todas as singularidades, nela reina a igualdade homogênea entre seus membros (cada cabeça equivale a outra cabeça), a densidade deve ser absoluta e por ultimo, nela predomina uma direção única. Que sobrepõe a todas as direções individuais e privadas, norte das massas (PELBART 2003, p. 25).

Nesse sentido, tem-se que a multidão, como um todo, é multifacetada, multicolorida, composta por inúmeras diferenças, sejam elas de cunho social, racial ou sexual, de modo que o desafio apresentado pelo conceito de multidão, deve consistir em fazer que uma multiplicidade social seja capaz de agir em comum, ao mesmo tempo em que se mantém internamente diferente. A importância desta capacidade do agir em comum, no intuito de perfectibilizar o real exercício da cidadania, encontra razão e fundamento na obra de Hardt e Negri (2012, p. 15):

Na medida em que a união não é uma identidade (como um povo) nem uniforme (como as massas), suas diferenças internas devem descobrir o comum, que the permite comunicar-se e agir em conjunto [...] podemos ter um primeiro vislumbre desta tendência democrática ao contemplarmos a genealogia das modernas resistências, revoltas e revoluções, que evidencia uma tendência para a organização cada vez mais democrática, das formas centralizadas de comando ou ditadura revolucionária para organizações em rede que deslocam a autoridade para relações colaborativas.

Percebe-se, assim, que a multidão não se baseia na unidade ou na indiferença, mas, sim, naquilo que se tem em comum. "O conceito de multidão desafia a verdade consagrada da soberania, uma vez que, em vez de ser um corpo político com uma parte que comanda e outras que obedecem, a multidão é carne viva que governa a si mesma" 
(HARDT; NEGRI, 2012, p. 140), sendo ela o único sujeito social capaz de realizar a democracia, ou seja, o governo de todos por todos.

\section{CONSIDERAÇÕES FINAIS}

Como se procurou demonstrar ao longo do presente artigo, em razão do corrente divórcio entre o povo e suas instituições de governo, concretiza-se uma violação ao princípio da soberania popular, razão pela qual, diante da inércia do eficaz exercício da democracia, surgem os mais variados movimentos advindos da união dos indivíduos, os quais procuraram - e procuram - sanar indignações provenientes de um governo que se mostra incapaz de compreender as necessidades dos povos excluídos da hegemonia.

Neste aspecto, poder-se-ia dizer que, a biopotência da multidão, se reunida, é capaz de resistir a toda e qualquer opressão. A multidão, como instrumento de resistência e composta por inúmeros indivíduos com capacidade de construção e transformação, demonstra que a sua união pode concretizar necessidades e anseios. Entende-se, assim, que os indivíduos, mantendo-se diferentes, podem, finalmente, descobrir pontos em comum que os permitam comunicar uns com os outros, no intuito de agir conjuntamente na busca de um bem comum.

A utilização da biopotência da multidão como estratégia de resistência, resultou em inúmeros exemplos de manifestações ocorridas ao longo dos séculos e, embora se tenha avançado significativamente ao adquirir direitos que antes eram negados, ainda há um longo caminho a construir. No mundo complexo e multifacetado no qual os indivíduos se encontram inseridos, nem sempre as razões que podem dar ensejo às suas mais profundas indignações estão beirando os olhos, mas, ainda sim, é evidente que existem motivos reais, os quais precisam, com urgência, de sua intervenção.

Com efeito, é possível verificar que, hoje, principalmente em razão da popularização da internet, capaz de articular com mais diferentes grupos sociais, uma onda de protestos e manifestações se tornam cada vez mais presentes, fomentando discussões acerca da atual conjuntura política e, mais do que isso, objetivando legitimar direitos para grupos minoritários e excluídos da classe hegemônica. 
Além das indignações fundadas por desejos pessoais, existem, ainda, motivos que ultrapassam as fronteiras do individualismo pessoal. Hoje, as listas de queixas contra a atual ordem global são intermináveis, seja no que diz respeito à pobreza, à fome, às desigualdades sociais, à corrupção, etc. Para Hessel (2011), vida não poderia significar outra coisa senão inteligência, afeto, paixão, cooperação. Se os motivos intrínsecos de indignação de cada indivíduo não forem suficientemente eficazes, necessário se faz, então, que estes saibam fazer uso do filantropismo, para que, assim, se possa atuar em prol daqueles que ainda não possuem seus direitos essenciais efetivados.

Assim, diante do aqui exposto, torna-se possível perceber que a potência da multidão, quando se reconhece em si mesma, é capaz de dar concretude àquilo que pulsa dentro de seus corpos para, enfim, ser capaz de perfectibilizar determinadas premissas em atos notórios que acabam, muitas vezes, dilacerados pelo passar do tempo. Essa verbalização palpável, capaz de representar o grupo em que os indivíduos se encontram inseridos ou, mais ainda, capaz de representar classes minoritárias incapazes de dar concretude àquilo que lhes é de direito, é exemplo de uma garantia de que, mesmo com a fragilidade latente do atual Estado Democrático de Direito, ainda é possível que os indivíduos sejam capazes de construir novos caminhos, mais justos e democráticos, quantas vezes sejam necessárias.

\section{REFERÊNCIAS}

AGAMBEN, Giorgio. A comunidade que vem. Belo Horizonte: Autêntica, 2013.

ARENDT, Hannah. A condição Humana. Tradução de Roberto Raposo. Rio de Janeiro: Forense Universitária, 2009.

AYUB, João Paulo. Introdução à analítica do poder de Michel Foucault. São Paulo: Intermeios, 2015.

BAUMAN, Zygmunt. Modernidade líquida. Rio de Janeiro: Jorge Zahar, 2001.

BAZZICALUPO, Laura. Biopolítica: um mapa conceitual. Tradução Luísa Rabolini. São Leopoldo: Editora Unisinos, 2017.

BITTENCOURT, Naiara Andreoli. A Biopolítica sobre a vida das mulheres e o controle jurídico brasileiro. Revista Gênero e Direito, Paraíba, v. 4, n. 3, ano 2015. Disponível em: 
<http://periodicos.ufpb.br/ojs2/index.php/ged/article/view/25963>. Acesso em: 13 out. 2017.

ESCOBAR, Antonius Jack Vargas. Genealogia e política. In: RIBEIRO, Renato Janine. Recordar Foucault. São Paulo: Brasiliense, 1985. p. 209-219.

FELÍCIO, Carmelita Brito de Freitas. Direitos humanos, biopolítica e condições de possibilidade da resistência em tempos sombrios. In: Associação Nacional de Direitos Humanos, Pesquisa e Pós-Graduação, 2008. Anais Eletrônicos. Disponível em: <www.andhep.org.br/anais/arquivos/Vencontro/gt1/gt01p06.pdf>. Acesso em: 24 out. 2017.

FOUCAULT, Michel. Ditos \& Escritos V - ética, sexualidade, política. Tradução Elisa Monteiro e Inês Autran Dourado Barbosa. Rio de Janeiro: Forense Universitária, 2004.

FOUCAULT, Michel. História da sexualidade: Vol. I: A vontade de saber. Rio de Janeiro, Edições Graal, 1977.

FOUCAULT, Michel. Microfísica do Poder. Rio de Janeiro, GRAAL, 1986.

FOUCAULT, Michel. Em defesa da Sociedade. São Paulo, Martins Fontes, 1999.

FOUCAULT, Michel. Nascimento da Biopolítica. Tradução de Eduardo Brandão. São Paulo: Martins fontes, 2008.

HARDT, Michael; NEGRI, Antônio. Multidão, guerra e democracia na era do Império. Tradução de Clóvis Marques. Rio de Janeiro: Editora Record, 2012.

HESSEL, Stéphane. Indignai-vos!. Tradução de Marly Peres. Reprodução Eletrônica Mensanapress Artesanato gráfico e editorial, 2011.

MARQUES, Wilson. Democracia na era da biopolítica e do biopoder: questão em análise. Tese (Doutorado em Direito) - Pontifícia Universidade Católica de São Paulo - PUC. São Paulo, 2016.

MONTEIRO, Maurício Gentil. $\mathbf{O}$ direito de resistência na ordem jurídica constitucional. Rio de Janeiro: Renovar, 2003.

MONTESQUIEU, Charlles de Secondat Baron de. O espírito das leis. Tradução de Cristina Murahco. São Paulo: Martins Fontes, 2005.

MOUFFE, Chantal. Democracia, cidadania e a questão do pluralismo. 2003. Disponível em: <http://livrozilla.com/doc/1672800/democracia--cidadania-e-aquest\%C3\%A3o-dopluralismo->. Acesso em: 24 out. 2017.

MÜLLER, Friedrich. Fragmento (sobre) poder constituinte do povo. Tradução de Peter Naumann. São Paulo: Revista dos Tribunais, 2004.

PELBART, Peter Pal. Vida Capital Ensaios de Biopolítica. São Paulo: Editora lluminuras LTDA, 2003.

RAWLS, John. Uma teoria da justiça. Tradução de Vamireh Chacon. Brasília: UnB, 1981.

REVEL, Judith. Michel Foucault: Conceitos essenciais. Tradução de Maria do Rosário e Nilton Milanez. São Carlos: Claraluz, 2005. 
SANTOS, André Leonardo Copetti; WERMUTH, Maiquel Ângelo Dezordi. Michel Foucault e a arqueologia/genealogia do poder: da sociedade disciplinar à biopolítica. Quaestio iuris, Rio de janeiro, v. 9, n. 1, p. 405-424, nov. 2017.

VIRNO, Paolo. Gramática da Multidão: para uma análise das formas de vida contemporâneas. São Paulo: Annablume, 2013.

WERMUTH, Maiquel Ângelo Dezordi; SANTOS, Luana

Marina. Biopoder e resistência: a (bio)potência da

multidão. RBSD - Revista Brasileira de Sociologia do

Direito, v. 5, n. 3, p. 108-131, set./dez. 2018.

Recebido em: 15/03/2018

Aprovado em: 21/07/2018 